\title{
12. Asylpolitik und Migrationsfragen
}

\section{Rosita Fibbi}

\section{OpenEdition \\ Journals}

Édition électronique

URL : http://journals.openedition.org/sjep/85

DOI : $10.4000 /$ sjep.85

ISSN : 1663-9677

\section{Éditeur}

Institut de hautes études internationales et du développement

\section{Édition imprimée}

Date de publication : 1 avril 2008

Pagination : 205-226

ISBN : 978-2-940415-02-1

ISSN : 1660-5926

Référence électronique

Rosita Fibbi, «12. Asylpolitik und Migrationsfragen », Schweizerisches Jahrbuch für Entwicklungspolitik [En ligne], 27-1 | 2008, mis en ligne le 29 mars 2010, consulté le 07 septembre 2020. URL : http:// journals.openedition.org/sjep/85; DOI : https://doi.org/10.4000/sjep.85 


\section{Asylpolitik und Migrationsfragen*}

D IE ANNAHME des neuen Asyl- und des neuen Ausländergesetzes im Jahr 2006 legte einen neuen Rahmen für die Aufnahmepolitik fest. 2007 war geprägt von der Umsetzung dieser Bestimmungen und von der Fokussierung auf die Integrationsfrage, die sich zum Schauplatz der Auseinandersetzung unter den Parteien entwickelte. Die Politisierung der Integration erreichte im angespannten Klima der Wahlkampagne im Herbst 2007 ein bisher beispielloses Ausmass. Die Vielzahl der parlamentarischen und Volksinitiativen $z u$ den gegenwärtig behandelten Gegenständen lässt leicht ersehen, dass die Thematik oben auf der politischen Agenda bleiben wird - trotz des Wechsels des für das Bundesamt für Migration zuständigen Bundesrates im Januar 2008'.

\subsection{Internationale Migrationspolitik}

\subsubsection{Weltforum über Migration und Entwicklung}

Im Herbst 2005 wurde mit der Veröffentlichung des Berichts der Global Commission on International Migration (GCIM), die im Auftrag der UNO die öffentliche Diskussion über die Bewältigung der Migration vorantreiben soll, die Entwicklungsthematik dauerhaft in den Mittelpunkt der Migrationsfrage auf der internationalen politisch-diplomatischen Agenda gerückt. Seitdem sind mehrere Meilensteine zu erwähnen: hochrangiger Dialog über internationale Migration und Entwicklung im Rahmen der Generalversammlung der Vereinten Nationen in New York im September 2006, gefolgt von einer Tagung in Brüssel vom 9. bis 11. Juli 2007 auf Initiative Belgiens, das das erste Treffen des Weltforums über Migration und Entwicklung (Global Forum on Migration and Development, GFMD) ausrichtete.

[D] Jahrbuch 2007, Nr. 1, „Internationale Entwicklungen“, S. 189.

Das GFMD soll als interaktives Diskussionsforum dienen, wo die politischen Entscheidungsträger Informationen und Ideen zu Migration und zu Entwicklung austauschen und mögliche neue Initiativen oder neue Multi-Stakeholder-Partnerschaften ausloten können, um handlungsorientierte Ergebnisse zu erzielen: strategische Empfehlungen, gute Praktiken, innovative Pilotprogramme, Partnerschaften und Lektionen aus den Erfahrungen der anderen. Zu diesem Zweck wurde das Treffen in einem innovativen Format in zwei Teile gegliedert: Am ersten Tag versammelten sich die Vertreter der Zivilgesellschaft, am zweiten und am dritten Tag fanden die Diskussionen der Regierungen statt. Das informelle, unverbindliche Verfahren des GFMD zeugt von der zugrunde liegenden Dynamik,

* Von Rosita Fibbi, Schweizerisches Forum für Migrations- und Bevölkerungsstudien, Universität Neuenburg; Institut d'anthropologie et sociologie, Universität Lausanne.

1 In den Bundesratswahlen am 12. Dezember 2007 wurde Christoph Blocher, Vorsteher des Eidgenössischen Justiz- und Polizeidepartements, nicht wiedergewählt; Eveline Widmer-Schlumpf wird ab dem 1. Januar 2008 dieses Departement übernehmen. 
die die Konfrontation durch Kooperation und durch Partnerschaft zwischen den Ländern, die von den Migrationsströmen betroffen sind, ersetzen soll.

Neben den Querschnittsthemen wie Menschenrechte, Gleichheit der Geschlechter und Kapazitätsaufbau betrafen die Arbeiten des Forums hauptsächlich drei Thematiken: 1. „Human Capital Development and Labor Mobility: Maximizing Opportunities and Minimizing Risks" (Entwicklung von Humankapital und Arbeitsmobilität: Chancen erhöhen und Risiken verringern); 2. „Remittances and other Diaspora Resources: Increasing their Net Volume and Development Value" (Heimatüberweisungen und andere Ressourcen der Diaspora: Nettovolumen und Entwicklungswert steigern); 3. „Enhancing Institutional and Policy Coherence and Promoting Partnerships" (Verbesserung der institutionellen und grundsatzpolitischen Kohärenz und Förderung von Partnerschaften).

Im September 2007 übergab Belgien das Zepter an die Philippinen, die den Vorsitz des GFMD übernommen haben. Die nächste Tagung des Forums wird im Oktober 2008 in Manila stattfinden.

Die Schweiz hatte bereits zuvor mit ihrer Berner Initiative die Global Commission on International Migration mit angeregt; sie bekräftigte ihr Interesse an diesem Prozess und möchte sich für die Vorbereitung des Treffens in Manila engagieren.

Dd Jahrbuch 2005, Nr. 1, ,Migrationsaussenpolitik“, S. 193-194.

\subsection{Schweizer Aussenpolitik}

\subsubsection{Ausdehnung der Personenfreizügigkeit auf Bulgarien und Rumänien}

Bulgarien und Rumänien sind am 1. Januar 2007 der Europäischen Union (EU) beigetreten. Die Gespräche zwischen der Schweiz und der EU über die Erweiterung der Personenfreizügigkeit auf die Staatsangehörigen dieser beiden neuen EU-Mitglieder haben im Herbst 2007 in einem sehr besonderen Klima begonnen. Auf internationaler Ebene ist dieses Klima von der beginnenden Opposition innerhalb der Europäischen Union gegen die Umsetzung der Personenfreizügigkeit für rumänische Staatsangehörige geprägt. Wie die Schweiz dazu geltend machte, hat der Druck auf die Südgrenze des Landes zugenommen, seit die italienische Regierung ihre Politik gegen rumänische Migranten, besonders Roma, verschärft hat ${ }^{2}$. Ähnliche Spannungen zeichnen sich auch in Frankreich $\mathrm{ab}^{3}$.

Hinzu kommen auf innerstaatlicher Ebene die Spannungen, die den Arbeitsfrieden in der Schweiz belasten, weil die Verhandlungen zwischen Arbeitgebern und Gewerkschaften über den neuen Gesamtarbeitsvertrag in der Baubranche an einem toten Punkt angelangt sind. Die Gewerkschaften hatten bekanntlich die vorherige Ausdehnung der Personenfreizügigkeit auf die zehn neuen EU-Mitglieder unterstützt und dabei auf flankierende Massnahmen, insbesondere die Stärkung der Gesamtarbeitsverträge, gesetzt, um das Risiko von Lohn- und Sozialdumping zu vermeiden.

메 Jahrbuch 2004, Nr. 1, ,Migrationspolitik“, S. 224-226.

2 „Schatten über Ausweitung der Personenfreizügigkeit. Auswirkungen italienischer Probleme“, Neue Zürcher Zeitung, 8. November 2007.

3 „Paris accélère les expulsions de Roms avant la trêve d'hiver“, Le Courrier, 10. November 2007. 
Die auf sieben Jahre befristete Übergangsregelung erlaubt der Schweiz, Zulassungsbeschränkungen zum Arbeitsmarkt aufrechtzuerhalten, und beinhaltet eine schrittweise Erhöhung der Anzahl der kurz- und langfristigen Aufenthaltsbewilligungen. Der Stichtag für den Beginn der Übergangsregelung wurde jedoch noch nicht festgelegt ${ }^{4}$.

Zur Diskussion steht ausserdem die Dauer der Schutzklausel, die es ermöglicht, selbst nach Ablauf der Übergangsregelung erneut Kontingente einzuführen, falls eine starke Zuwanderung erfolgen sollte. Die Schweiz möchte, dass die Dauer der speziellen Schutzklausel auf fünf Jahre festgesetzt wird. Die EU wünscht, dass diese Klausel zehn Jahre nach dem EU-Beitritt dieser Länder ausläuft, wie es für die vorherige Osterweiterung der Fall war ${ }^{5}$.

\subsubsection{Migrationspartnerschaften: für ein globales Migrationsmanagement}

Die früher hauptsächlich durch innenpolitische Interessen bestimmte Migrationspolitik nimmt seit einigen Jahren aussenpolitische Dimensionen an. Angesichts der Herausforderungen, die mit der wachsenden Zahl der Migranten und den komplexeren Migrationsströmen zusammenhängen, eignen sich unilaterale Massnahmen immer weniger, um die Migration zu steuern. Die Schweiz hat diesbezüglich mit der Berner Initiative im Jahr 2001 und mit der Unterstützung der Schaffung der Global Commission on International Migration (GCIM) im Jahr 2003 einen multilateralen Reflexionsprozess angeregt.

Auf der Vollzugsebene ist die Schweiz wie andere Empfangsländer mit Schwierigkeiten bei der Ausschaffung von abgewiesenen Asylsuchenden und Personen ohne gültige Aufenthaltserlaubnis in ihr Herkunftsland konfrontiert. Anlässlich der Verhandlungen über den Wegweisungsvollzug betonen bestimmte Herkunftsländer, dass die Rückübernahme ihrer Staatsangehörigen allein den schweizerischen Interessen entspreche, und fordern Gegenleistungen, die zum Teil über den Migrationsbereich hinausgehen.

Der Bundesrat hat in diesem Kontext die Interdepartementale Arbeitsgruppe IDAG Migration beauftragt, Mittel und Wege zu prüfen, um die aussenpolitischen Instrumente auch im Bereich Migration und Rückkehr einzusetzen. Die Gruppe definiert dieses Instrument wie folgt: „Längerfristiges Ziel der Schweiz muss es sein, mit den Herkunfts- und Transitstaaten von Migrantinnen und Migranten Migrationspartnerschaften zu etablieren. Migrationspartnerschaften streben nach einem ausgewogenen und fairen Interessenausgleich bei Problemstellungen, welche den beteiligten Staaten durch Aus-, Ein- und Rückwanderung entstehen." 6

Die Migrationspartnerschaften sind heute im Ausländergesetz (AuG) verankert; dieses Dispositiv ist am 1. Januar 2007 in Kraft getreten.

4 „Schweiz legt Wert auf Schutzmechanismus. Vor Ausdehnung der Personenfreizügigkeit auf Rumänien und Bulgarien“, Neue Zürcher Zeitung, 10. Juli 2007. „Difficiles discussions sur la Roumanie et la Bulgarie“, Le Temps, 8. November 2007.

5 Bundesamt für Migration (BFM), Vierte Verhandlungsrunde zur Ausdehnung des Freizügigkeitsabkommens auf Bulgarien und Rumänien, Medienmitteilung, 12. Dezember 2007.

6 Interdepartementale Arbeitsgruppe „Aussenpolitik im Migrations- und Rückkehrbereich“, Schlussbericht der IDAG Migration, Bern, 2004, S. 13. Siehe auch Claudia De Matos und Denise EfionayiMäder, Origine, définition et approches de la notion de partenariats de migration en Suisse, Schweizerisches Forum für Migrations- und Bevölkerungsstudien, Universität Neuenburg, 2007. 


\subsubsection{Illegale Zuwanderung aus Afrika bremsen}

Definitionsgemäss gibt es keine Statistiken zur illegalen Migration und noch weniger zu den dabei aufgetretenen Todesfällen. Nur das Hochkommissariat der Vereinten Nationen für Flüchtlinge (HCR) gibt bei tragischen Ereignissen öffentlich Zahlen an. Am 14. Dezember 2007 sprach das HCR auf einer Pressekonferenz von mindestens 200 Personen, die allein in der Woche zuvor bei verschiedenen Unfällen in der Türkei, auf den Kanarischen Inseln und im Jemen ertrunken oder auf hoher See verschwunden waren? ${ }^{7}$.

Um auf diese Realitäten zu reagieren, hat sich das Bundesamt für Migration (BFM) mit der Internationalen Organisation für Migration (IOM) zusammengeschlossen, um erstmals in Afrika ein Informationsprogramm durchzuführen und Jugendliche für die Risiken der illegalen Auswanderung zu sensibilisieren ${ }^{8}$. Das Programm wurde in einigen Regionen in Kamerun und Nigeria durchgeführt; es trägt den bedeutungsschweren Namen „A la mémoire de Fodé et Yaguine“ (Zum Gedenken an Fodé und Yaguine), zwei 14- und 15-jährige Guineer, die einen berührenden Brief an die ,Mitglieder und Verantwortlichen von Europa“" bei sich trugen, als sie 1999 tot im Fahrwerk eines Flugzeuges aufgefunden wurden.

\subsubsection{Förderung der Rückkehr von abgewiesenen Asylsuchenden}

Das BFM hat ein Rückkehrhilfeprogramm für Staatsangehörige aus dem Balkan mit einem Flüchtlingsausweis, einer vorläufigen Aufenthaltsbewilligung F oder $\mathrm{N}$ sowie für abgewiesene Asylsuchende in die Wege geleitet. Das Programm, das Ende 2007 abgeschlossen wurde, richtete sich in erster Linie an Mitglieder der ethnischen Minderheiten und an verletzliche Gruppen: Dazu zählen alleinstehende Frauen, traumatisierte Menschen und ältere Menschen. Für diese wurden nach der Rückkehr in die Heimat Folgemassnahmen angeboten.

Daneben gibt es die individuelle Hilfe für Asylsuchende und Flüchtlinge: Organisation der Reise, Pauschale von 1000 Schweizer Franken pro Erwachsenen und 500 Franken pro Kind sowie eine Zusatzhilfe. Das BFM arbeitet mit der IOM und mit der Direktion für Entwicklung und Zusammenarbeit (DEZA) zusammen; Letztere konzentriert ihre Hilfe vorrangig auf die Stabilisierung dieser Region. Das BFM hat die Rückkehrhilfe für abgewiesene Asylsuchende aus der Europäischen Union (EU) wegen der Missbräuche durch Roma aus Rumänien aufgehoben ${ }^{10}$.

Zudem arbeitet Bern bereits im Rahmen des Pilotprojekts „Return“ (Organisation von gemeinsamen Flügen zur Ausschaffung von renitenten illegalen Personen) mit den EU-Ländern zusammen ${ }^{11}$. Schliesslich ist im Jahr 2007 kein neues Rückübernahmeabkommen in Kraft getreten.

Dahrbuch 2003, Nr. 1, ,Rückkehr und Rückführung“, S. 220.

7 HCR, Over 200 boat people feared drowned in separate incidents, Pressekonferenz, 14. Dezember 2007, <http://www.unhcr.org/cgi-bin/texis/vtx/news/opendoc.htm?tbl=NEWS\&id=47626dbe5> (Konsultation: 14. Dezember 2007).

8 BFM, Sensibilisierungskampagne über illegale Migration in Afrika, Medienmitteilung, 28. November 2007. Charlie Pegg, „La Suisse éduque les migrants à rester chez eux“, Terra economica, 18 Juli 2007, <http://www.terra-economica.info> (Konsultation: 15. November 2007).

9 <http://www.observatoirecitoyen.be/article.php3?id_article=515> (Konsultation: 14. Dezember 2007).

10 ATS, Aide au retour supprimée pour les requérants provenant de l'UE, 17. Mai 2007.

$11<$ http://www.ch.iom.int/programme/rif.html> (Konsultation: 15. November 2007). 
Nach teilweise tödlichen Zwischenfällen bei der Ausschaffung von irregulär anwesenden Personen oder abgewiesenen Asylsuchenden hat das Parlament Schritte unternommen, um das Verfahren und den Einsatz von Zwangsmitteln zu regeln. Der Entwurf des Gesetzes über die Anwendung von polizeilichem Zwang (ZAG), mit dem sich der Nationalrat im Oktober 2007 befasste, sieht die Möglichkeit vor, eventuell Taser (Elektroschockwaffen) einzusetzen. Taser werden in anderen Ländern bereits verwendet; sie haben mehrfach zum Tod von abgewiesenen Personen geführt und werden deshalb von der Schweizerischen Flüchtlingshilfe (SFH) vehement abgelehnt ${ }^{12}$.

\subsection{Asylpolitik}

\subsubsection{Asylstatistik}

\section{$\square 2006$ eingereichte Asylgesuche}

Im Jahr 2006 haben 10537 Personen in der Schweiz um Asyl nachgesucht. Dies entspricht einer leichten Zunahme (4,7\%) gegenüber 2005. Damit wird die stark rückläufige Tendenz, die die beiden Vorjahre prägte (-30\% im Jahr 2005, -32\% im Jahr 2004), umgekehrt. Die Entwicklung in Europa ist uneinheitlich: Einige Länder (Schweden, Polen, Niederlande) sind mit zunehmenden Asylgesuchen konfrontiert, andere (Deutschland, Belgien, Frankreich, Grossbritannien) verzeichnen eine Abnahme.

\section{Grafik 12.1: Entwicklung der Asylgesuche, 1996-2006}

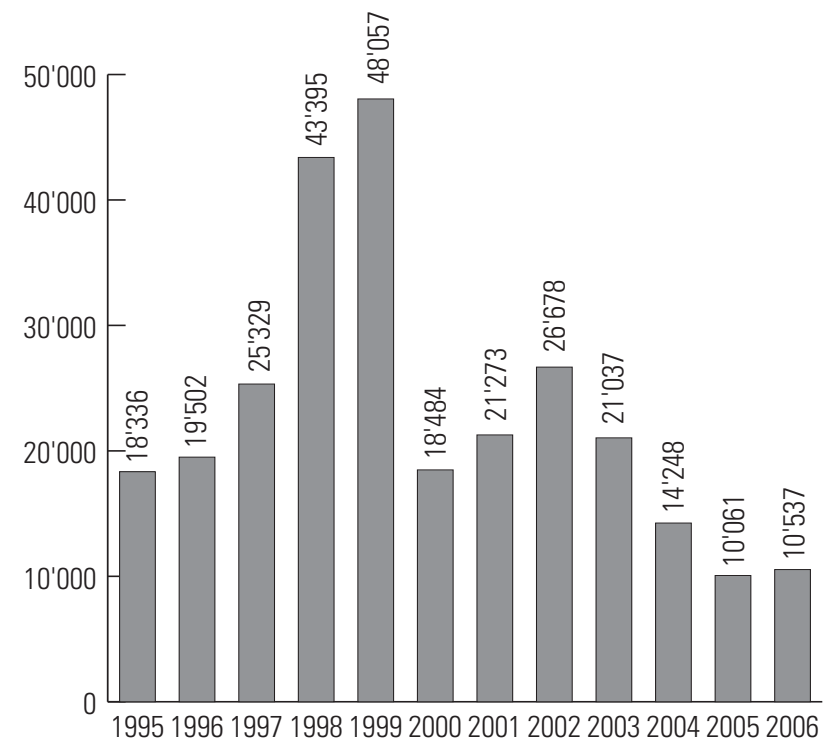

Quelle: BFM, Asylstatistik, Januar 2007

12 SFH, Zwangsanwendungsgesetz: Keine Ausschaffung um jeden Preis, Pressemitteilung, 2. Oktober 2007. 
Seit Anfang der 2000er-Jahre stammen die zahlenmässig stärksten Gruppen von Asylsuchenden aus der Balkanregion. Serbien - heute von Montenegro getrennt - stand zwar 2006 noch an erster Stelle der Herkunftsländer (11,6\%), aber der Anteil dieser Region ist markant zurückgegangen. Dagegen hat die Anzahl Asylsuchende aus Eritrea (+655\%) und China (+446\%) stark zugenommen; diese beiden Staaten rückten 2006 zum zweitwichtigsten bzw. zum fünftwichtigsten Herkunftsland auf. Irak bildet mit einer Zunahme um 74\% das drittwichtigste Herkunftsland, gefolgt von der Türkei. In 3\% der Fälle konnte die nationale Herkunft der Asylsuchenden nicht ermittelt werden.

Tabelle 12.1: In der Schweiz eingereichte Asylgesuche, 2005-2006, nach Herkunftsland

\begin{tabular}{llrrr}
\hline Rang & Nation & Asylgesuche 2005 & Asylgesuche 2006 & in \% der Gesamtsumme \\
\hline 1. & Serbien und Montenegro & 1506 & 1225 & 11.6 \\
\hline 2. & Eritrea & 159 & 1201 & 11.4 \\
\hline 3. & Irak & 468 & 816 & 7.7 \\
\hline 4. & Türkei & 723 & 693 & 6.6 \\
\hline 5. & China & 87 & 475 & 4.5 \\
\hline 6. & Russland & 375 & 426 & 4.0 \\
\hline 7. & Sri Lanka & 233 & 328 & 3.1 \\
\hline 8. & Staat + Kontinent unbekannt & 314 & 319 & 3.0 \\
\hline 9. & Iran & 291 & 302 & 2.9 \\
\hline 10. & Georgien & 397 & 287 & 2.7 \\
\hline & übrige Nationen & 47405 & 42.4 \\
\hline Insgesamt & $\mathbf{9 2 9 3}$ & $\mathbf{1 0 5 3 7}$ & $\mathbf{1 0 0}$ \\
\hline
\end{tabular}

Quelle: BFM, Asylstatistik 2006, Januar 2007.

In Bezug auf die Zahl der Asylgesuche gemessen an der Wohnbevölkerung hat sich im Jahr 2006 die Rangliste unter den europäischen Ländern nicht wesentlich verändert: Die Schweiz belegte erneut den dritten Platz - hinter Österreich und Schweden, aber vor Norwegen (siehe Grafik 12.2). Dagegen ist die Anzahl eingereichter Asylgesuche auf 100000 Einwohner in allen Ländern stark zurückgegangen, in Österreich z.B. von 489 auf 387 und in der Schweiz von 293 auf 234.

\section{Grafik 12.2: Anzahl Asylgesuche auf 100000 Einwohner aus Westeuropa}

(1. Januar 2005 bis 30. September 2006)

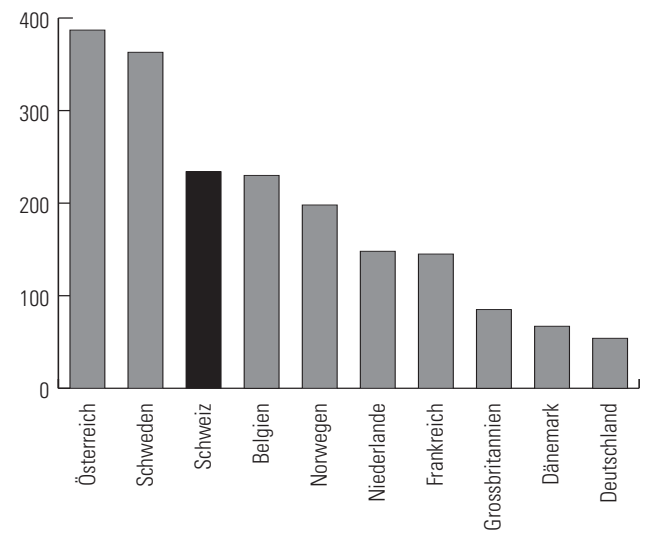

Quelle: BFM, Asylstatistik 2006, Januar 2007. 


\section{Asylgewährung}

2006 gewährte das BFM 1857 Personen Asyl, davon 1024 im Rahmen des Familiennachzugs (55\%). Dies entspricht einer Zunahme der Anerkennung des Flüchtlingsstatus um 24\% gegenüber 2005. Angesichts des Rückgangs der eingereichten Gesuche erhöhte sich die durchschnittliche Anerkennungsrate 2006 insgesamt auf 19,5\% (+43\%) gegenüber 13,6\% im Jahr 2005 und 9,2\% im Jahr 2004. Dieser Mittelwert beinhaltet je nach Staatsbürgerschaft sehr variable Anerkennungsraten: Für Personen aus Eritrea beträgt sie etwa 86\%, für Personen aus Tunesien $64 \%$, für Personen aus der Türkei $54 \%$ und für Personen aus Togo 54\%. Für Personen aus Sri Lanka sinkt die Anerkennungsrate auf 28\%, für Personen aus dem Irak auf $16 \%$ und für Personen aus China auf $11 \%$.

5193 Personen wurden 2006 vorläufig aufgenommen (17\% mehr als im Vorjahr). Wie bereits 2005 handelte es sich hauptsächlich um Staatsbürger aus dem Irak und aus Serbien.

Der seit 2004 beobachtete Rückgang bei den Nichteintretensentscheiden (NEE) setzte sich 2006 mit einer weiteren Verringerung um 27\% gegenüber dem Vorjahr fort. Auch die abgelehnten Asylgesuche gingen auf 5840 im Jahr 2006 zurück (16\% weniger als 2005).

Tabelle 12.2: Personen im Asylbereich (Stand: Ende Dezember 2005 und 2006)

\begin{tabular}{lrrr}
\hline & $\mathbf{3 1 . 1 2 . 2 0 0 5}$ & $\mathbf{3 1 . 1 2 . 2 0 0 6}$ & Variation (\%) \\
\hline Gesamte Personen & 71770 & 68131 & -5.1 \\
\hline anerkannte Flüchtlinge & 23577 & 23262 & -1.3 \\
\hline Vorläufige Aufnahme & 24453 & 25244 & 3.2 \\
\hline Gesamte Personen im Verfahrensprozess & 13694 & 11653 & -14.9 \\
\hline Gesamte Personen im Vollzugsprozess & 10046 & 7972 & -20.6 \\
\hline
\end{tabular}

Quelle: BFM, Asylstatistik 2006, Januar 2007.

Wie in der Vergangenheit (ausser im Jahr 2000 mit der freiwilligen Rückkehr von Personen aus dem Kosovo) ist ein Grossteil der Ausreisen - 50\% im Jahr 2006 - unkontrolliert ${ }^{13} .1643$ anerkannten Flüchtlingen wurde das Asyl entzogen, da sie in ihrer Heimat keinerlei Gefahren mehr ausgesetzt waren. Ferner hob das BFM die provisorische Aufnahme von 4401 Personen auf: Wie schon 2005 handelte es sich bei den Betroffenen mehrheitlich um Personen aus Serbien und aus Bosnien-Herzegowina, die in den Genuss einer kantonal geregelten humanitären Aufnahme gekommen waren.

Insgesamt sank die Zahl der Personen im Asylbereich im Jahr 2006 auf 68131 gegenüber 71770 Personen Ende Dezember 2005 (-5,1\%). Diese Personen machen 4,5\% der ausländischen Bevölkerung und 0,9\% der Wohnbevölkerung in der Schweiz aus.

13 Als unkontrollierte Ausreisen gelten die freiwillige, aber nicht angekündigte Rückkehr, die Weiteremigration in ein Drittland sowie der Verbleib in der Schweiz ohne offizielle Bewilligung (SansPapiers). 


\subsubsection{Ausführungsverordnung und Revision des Asylgesetzes}

Das neue Asylgesetz (AsylG), das in der Volksabstimmung von September 2006 angenommen wurde, sieht insbesondere das Nichteintreten auf Asylgesuche vor, wenn die Person ohne Ausweispapiere einreist oder sich in einem als sicher eingestuften Drittland aufgehalten hat; zudem verschärft das neue Gesetz die Zwangsmassnahmen bei der Ausschaffung und streicht die Sozialhilfe für alle abgewiesenen Asylsuchenden. Dagegen erleichtert es für Inhaber einer humanitären Aufnahmebewilligung den Zugang zum Arbeitsmarkt.

ㅁ] Jahrbuch 2006, Nr. 1, ,Verabschiedung der Asylgesetzrevision“, S. 204-206.

Das Gesetz tritt gestaffelt in Kraft. Der bereits 2007 umgesetzte erste Teil der AsylG-Bestimmungen betrifft den Nichteintretensgrund der Papierlosigkeit, der im Vorfeld der Volksabstimmung von September 2006 heftig bekämpft worden war. Die SFH hat 993 seit dem 1. Januar 2007 gefällte Nichteintretensentscheide geprüft und dabei festgestellt, dass die strengsten Kriterien angewandt wurden, sodass sogar Asylsuchende aus Ländern wie Irak, Sri Lanka oder Afghanistan, in denen Gewalt herrscht, abgewiesen wurden ${ }^{14}$.

Ein Jahr nach der Abstimmung zieht deshalb die SFH die Bilanz, dass der Bundesrat sein Versprechen an das Stimmvolk nicht eingehalten habe, nämlich auf den Fall von tatsächlich schutzbedürftigen Asylsuchenden einzutreten, selbst wenn sie keine Reisepapiere vorweisen könnten. Der Bundesrat hat in der Ausführungsverordnung zum Asylgesetz Massnahmen angenommen, die das Eintreten verhindern. Damit hat der Bundesrat die gesetzlichen Schutzmechanismen ihres Sinnes entleert, wie der Sprecher der SFH Yann Golay erklärt ${ }^{15}$.

Im Januar 2008 wird der zweite Teil des neuen Asylgesetzes, der den Sozialhilfestopp für alle abgewiesenen Asylsuchenden beinhaltet, in Kraft treten. Der Ausschluss von der Sozialhilfe war im April 2004 eingeführt worden, betraf aber bislang nur Asylsuchende mit einem rechtskräftigen NEE.

미 Jahrbuch 2007, Nr. 1, ,Referendum und Abstimmungsresultat“, S. 196-198.

Die Sozialhilfe wird aus dem Budget des Bundes gezahlt, während die Nothilfe aus dem Budget der Kantone und Gemeinden bestritten wird ${ }^{16}$. Ab dem 1. Januar 2008 werden die Kantone für die Nothilfe, die sie an von der Sozialhilfe ausgeschlossene Personen leisten, eine Fallpauschale von 6000 Franken beziehen (gegenüber 1800 Franken heute).

Das Eidgenössische Justiz- und Polizeidepartement (EJPD) ist über den Anstieg der Asylgesuche eritreischer Personen - Deserteure und Dienstverweigerer besorgt (siehe oben Abschnitt 12.3.1); es führt diese Entwicklung, die im übrigen Europa nicht beobachtet wird, auf die „Sogwirkung“ eines Urteils der Asylrekurskommission (ARK) zurück ${ }^{17}$. Gemäss dem Urteil der ARK sollten diese Personen als Flüchtlinge anerkannt werden. Um den Trend aufzuhalten, erarbeitet das EJPD einen dringlichen Bundesbeschluss zur Veränderung des Asylge-

14 „Querelle autour des requérants sans papier“, Le Temps, 20. Juli 2007.

15 SFH, Der Bundesrat hält sein Versprechen nicht, Medienmitteilung, 24. Oktober 2007.

16 BFM, Sozialhilfe für Asylsuchende, vorläufig Aufgenommene, Schutzbedürftige, rechtliche Informationen, 13. Dezember 2007.

17 Das im Januar 2007 geschaffene Bundesverwaltungsgericht hat die Aufgaben der ARK übernommen (siehe Abschnitt 12.3.3 unten). 
setzes, damit die automatische Gewährung des Flüchtlingsstatus in diesen Fällen ausgesetzt und wieder ein Einzelverfahren eingeführt wird.

Die SFH bezeichnet diesen Vorschlag als surrealistisch, da die Schweiz Desertion gar nie als Asylgrund anerkannt habe. Dagegen, so die SFH, habe die ARK festgestellt, dass die Deserteure gravierenden Sanktionen ausgesetzt und in dieser Hinsicht schutzwürdig seien. Der Sprecher der SFH kommentierte, Christoph Blocher könne Desertion oder Gewissensverweigerung nicht ausschliessen, weil dies gar keine Asylgründe seien; wenn er Misshandlung ausschliesse, verletze er das Gesetz und sogar die Verfassung ${ }^{18}$.

\subsubsection{Die Rechtsprechung des Bundesverwaltungsgerichts}

Seit einiger Zeit sind zwischen Justizminister Christoph Blocher und den Gerichtsinstanzen, die mit der Auslegung der Gesetzesanwendung ${ }^{19}$ beauftragt sind, besonders im Asylbereich Spannungen spürbar.

[D] Jahrbuch 2007, Nr. 1, „Die Rechtsprechung der Asylrekurskommission“, S. 198-199.

Das neue Bundesverwaltungsgericht, das seit Januar 2007 tätig ist, hat unter anderem die bisher der Asylrekurskommission obliegenden Aufgaben und damit auch die Spannungen zwischen Exekutive und Judikative geerbt. In einem Grundsatzentscheid vom 11. Juli 2007 kam das BVGer zum Schluss, dass ein Nichteintretensentscheid nur dann gerechtfertigt sei, wenn nach einem Schnellverfahren das Fehlen der Flüchtlingseigenschaft feststehe. Wenn dies nicht der Fall sei, müssten im Rahmen eines ordentlichen Verfahrens die ,weiteren Abklärungen" vorgenommen werden.

Das BFM sieht seine eigenen Verfügungen im Entscheid des Bundesverwaltungsgerichts bestätigt ${ }^{20}$. Nach Auffassung der SFH wird der Justizentscheid des neuen BVGer durch die Bestimmungen der Verordnungen über die Revision des Asylgesetzes ausgehebelt. Die Dachorganisation der Flüchtlingshilfswerke ist konsterniert über die Missachtung der Gewaltentrennung im Asylbereich ${ }^{21}$.

\subsubsection{Monitoring der Nichteintretensentscheide}

Seit 2004 sind Asylsuchende, auf deren Asylgesuch nicht eingetreten wurde, von der Sozialhilfe ausgeschlossen und erhalten auf Ersuchen nur Nothilfe. Drei Jahre nach der Umsetzung der Entscheidung zieht das BFM eine positive Bilanz zu dieser Regelung: Es wurden weniger offensichtlich unbegründete Asylgesuche eingereicht; die Zahl der Nothilfebezüger ist begrenzt (eine von drei Personen) und ebenfalls rückläufig ${ }^{22}$.

Solidarité sans frontières ${ }^{23}$ reagierte mit der Feststellung, dass das Schicksal der Personen mit einem NEE grösstenteils unbekannt bleibt, weil nur $20 \%$ eine

18 „Blocher prend les déserteurs érythréens dans son collimateur“, Le Courrier, 25. Oktober 2007.

19 „La montée en puissance des juges“, Le Temps, 13. Januar 2007.

20 „Nouvelle Loi sur l'asile: les premiers jugements suscitent la controverse“, Le Temps, 24. August 2007.

SFH, Der Bundesrat hält sein Versprechen nicht, Medienmitteilung, 24. Oktober 2007.

2 BFM, Positive Gesamtbilanz nach 3 Jahren Sozialhilfestopp, Medienmitteilung, 6. September 2007.

3 Die NRO Solidarité sans frontières ist aus der Fusion von zwei Vereinen hervorgegangen: der Bewegung für eine offene, demokratische und solidarische Schweiz (BODS) und der Asylkoordination Schweiz (AKS). 
„kontrollierte Ausreise“ ${ }^{24}$ vornehmen; gemäss den Kontakten vor Ort tauchen die „NEE“ in die Illegalität unter oder suchen Hilfe in einem anderen Land, aber nur wenige kehren in ihr Herkunftsland zurück.

\subsubsection{Gründung der Schweizerischen Beobachtungsstelle für Asyl- und Ausländerrecht}

Die Koalition von Bürgerinnen und Bürgern, die die Unmenschlichkeit und Unwirksamkeit des Asyl- und des Ausländerrechts anprangerte, engagierte sich nach der Annahme der beiden Gesetze in der Volksabstimmung von September 2006 dafür, eine „Schweizerische Beobachtungsstelle für Asyl- und Ausländerrecht“ zu gründen. Aus der Überzeugung heraus, dass ,die neuen Gesetze - welche als notwendiges Mittel im Kampf gegen den Missbrauch präsentiert werden - tatsächlich Flüchtlinge gefährden, neue Sans-Papiers, mehr irreguläre Situationen und teilweise auch neue Kriminalität produzieren "25, führte diese Koalition aus Frauen und Männern aller Parteien, Berufsstände und Kantone am 8. Februar 2007 die Gründungsversammlung der neuen Beobachtungsstelle durch. Diese soll überwachen, dass die Gesetzesanwendung im Einklang mit dem Völkerrecht und mit der humanitären Tradition der Schweiz erfolgt - im Bewusstsein, dass sich die schweizerische Migrationspolitik weiter verschärfen wird.

Die Beobachtungsstelle soll finanziell unabhängig sein; sie sammelt und verbreitet faktische Informationen, die auf konkreten Beispielen in der ganzen Schweiz basieren. Sie erstellt Karteien mit realen Fallbeschreibungen, deren Echtheit sorgfältig geprüft wird und die nach Auffassung der Moderatoren der Beobachtungsstelle auf eine unmenschliche oder völkerrechtswidrige Anwendung des Asyl- und des Ausländergesetzes hindeuten. Die Beobachtungsstelle leistet keine juristische Verteidigung der betroffenen Personen, sondern engagiert sich für die Sensibilisierung der öffentlichen Meinung durch Informationen an die Medien, Parlamentsmitglieder, Flüchtlings- und Ausländerhilfsorganisationen und an die internationalen Institutionen. Damit spielt sie gewissermassen eine Vermittlerrolle zwischen der Realität, wo die Gesetze konkret angewandt werden, und den Akteuren in der öffentlichen Debatte über Asyl und Migration.

Das Observatoire du droit d'asile et des étrangers in Genf hat im April 2007 als Pilotprojekt die Tätigkeit aufgenommen ${ }^{26}$. In den nächsten Monaten sollen zwei weitere regionale Projekte in St. Gallen und in Lugano eingeführt werden. Eine zentrale Struktur, die sich vor allem mit Analysen befasst, wird in Bern angesiedelt ${ }^{27}$.

\footnotetext{
„Peu de requérants déboutés d'office prétendent à une aide d'urgence“, Le Temps, 7. September 2007. $<$ http://www.migrantsrightswatch.ch> (Konsultation: 14. Dezember 2007).

<http://www.stopexclusion.ch/beobachtungsstelle> (Konsultation: 14. Dezember 2007).

7 Provisorischer Vorstand der Schweizerischen Beobachtungsstelle für Asyl- und Ausländerrecht, Newsletter, Oktober 2007.
} 


\subsubsection{Entwicklung der Einreisen in die Schweiz}

Die Tendenz zeichnet sich bereits seit einigen Jahren ab: Das Freizügigkeitsabkommen (FZA) mit der EU wirkt sich weiterhin auf die Zusammensetzung der ausländischen Wohnbevölkerung in der Schweiz aus. Im August 2007 wurde bei den Staatsangehörigen aus den 27 Mitgliedsstaaten der Europäischen Union (EU 27) und der Europäischen Freihandelsassoziation (EFTA) ein Anstieg um $3,2 \%$, bei den Staatsangehörigen aus Nicht-EU- bzw. Nicht-EFTA-Staaten ein Rückgang um $1,1 \%$ gegenüber dem Vorjahr verzeichnet ${ }^{28}$. Im August 2007 stammten $60 \%$ der in der Schweiz lebenden Ausländer aus der EU oder aus der EFTA, im Jahr 2003 waren es $55 \%$.

Im Juni 2007 trat die letzte Etappe des FZA in Kraft: Staatsangehörige der EU 15 können sich in der Schweiz niederlassen, sofern sie einen Arbeitsvertrag besitzen. Serge Gaillard vom Staatssekretariat für Wirtschaft (SECO) zieht eine positive Bilanz zur Öffnung und kommentiert, die Zunahme der Anzahl Ausländerinnen und Ausländer liege unter dem Durchschnitt der letzten zehn Jahre; die Gewerkschaften jedoch stellen in den Sektoren ohne Gesamtarbeitsvertrag Druck auf die Löhne fest.

Die vollständige Freizügigkeit mit der EU 15 unterliegt noch einer einjährigen Probezeit. Wenn die Immigration aus den alten EU-Mitgliedsstaaten zwischen dem 1. Juni 2007 und dem 31. Mai 2008 mehr als 10\% über dem Durchschnitt der letzten drei Jahre liegt, könnte eine Schutzklausel ausgelöst werden, um für eine Dauer von zwei Jahren erneut Bewilligungskontingente einzuführen ${ }^{29}$. Die Bundesversammlung wird im Sommer 2008 entscheiden, ob die Abkommen über die Personenfreizügigkeit weitergeführt werden sollen; dieser Beschluss unterliegt dem fakultativen Referendum.

Der Grossteil (76\%) der in den letzten zehn Jahren in die Schweiz eingewanderten ausländischen Erwerbspersonen besitzt eine Ausbildung auf Sekundarstufe oder Tertiärstufe, was den Zielen der neuen Aufnahmepolitik entspricht ${ }^{30}$.

\subsubsection{Regelung der Aufnahmen: offene Fragen}

Das neue Ausländergesetz (AuG) betrifft Staatsangehörige aus Drittländern und verankert den Grundsatz der selektiven, auf hoch qualifizierte Berufe beschränkten Einwanderung, während die bilateralen Verträge den freien Personenverkehr für EU-EFTA-Bürger vorsehen. Das AuG verbessert die Integration der in der Schweiz aufgenommenen Ausländerinnen und Ausländer, weil es ihnen die freie Wahl des Arbeits- und Wohnortes gewährt. Das Gesetz verknüpft den Familiennachzug mit dem Besuch von Sprach- und Integrationskursen.

Jahrbuch 2006, Nr. 1, „Ausländergesetz“, S. 210.

30 BFS, Einwanderung gut qualifizierter Ausländerinnen und Ausländer, Medienmitteilung, 20. Februar 2007. 
Im Rahmen der Vernehmlassung zur Verordnung über die Aufnahme von Staatsangehörigen aus Drittländern, aus denen nur besonders hoch qualifizierte Erwerbstätige rekrutiert werden können, haben Hochschul- und Forschungskreise Besorgnis geäussert. Sie befürchten wachsende Probleme wegen der neuen Vorschriften, die die Möglichkeit einschränken, nichteuropäische Studierende und Forschende in die Schweiz zu holen und hier zu behalten, obwohl sich der internationale Wettbewerb unter den Hochschulen heute verschärft ${ }^{31}$.

Die Präsidenten des Rats der Eidgenössischen Technischen Hochschulen sowie die Rektoren lehnen besonders die Befristung des Aufenthalts für Studierende auf höchstens acht Jahre ab; diese Dauer ist ihres Erachtens viel zu kurz, um einen Bachelor, einen Master und ein Doktorat abzuschliessen. Ausserdem missbilligen sie das Verbot für ausländische Studierende, während der ersten sechs Monate eine Nebenerwerbstätigkeit auszuüben. Schliesslich bezeichnen sie es als absurd, dass Studierende mit einem Doktorat nach Hause geschickt werden, wenn sie nicht unverzüglich nach Studienabschluss eine Stelle finden. Sie plädieren dafür, Akademiker vom Inländervorrang und von den kantonalen Aufenthaltsbewilligungs-Kontingenten auszunehmen.

Die neue Zuwanderungspolitik soll die direkt mit dem Arbeitsmarkt verknüpfte Zuwanderung erhöhen, die mit dem Familiennachzug verbundene Zuwanderung aber verringern. Erstmals seit 2007 lag der Anteil der Einreisen im Rahmen des Familiennachzugs unter dem Anteil der Einreisen im Rahmen der Erwerbstätigkeit $(36,2 \% \text { bzw. } 37,6 \%)^{32}$.

Während in Frankreich gegenwärtig die Polemik über die Einführung von DNATests für die Familienzusammenführung Schlagzeilen macht, entdeckt die öffentliche Meinung, dass solche Tests in der Schweiz und in anderen europäischen Ländern wie z.B. dem Vereinigten Königreich bereits seit 2004 zum Einsatz kommen. In der Schweiz sind im Wesentlichen Staatsangehörige aus verschiedenen afrikanischen Ländern betroffen, aber auch - unter anderem - aus Afghanistan, Irak und Sri Lanka ${ }^{33}$. Die DNA-Tests werden im neuen Ausländergesetz nicht erwähnt, weshalb die NRO Humanrights.ch von einer gesetzlichen Grauzone spricht ${ }^{34}$.

Schliesslich befassen sich weder das neue Gesetz noch die Verordnung mit der Frage der Sans-Papiers, obwohl dieses Problem bereits seit 2000 mit den ersten Mobilisierungsbewegungen von abgewiesenen Personen aus dem Kosovo im öffentlichen Rampenlicht steht. Die Frage beinhaltet mehrere Facetten, darunter diejenige, die der freisinnige Nationalrat John Dupraz für den Europarat untersucht hat. John Dupraz erstattete einen schonungslosen Bericht über die als „moderne Sklaverei“ beschriebenen Arbeitsbedingungen der Sans-Papiers in der europäischen Landwirtschaft ${ }^{35}$. Der Bericht plädiert unter anderem für verein-

31 „Colère des scientifiques : trop de barrières aux étudiants étrangers“, Le Temps, 9. September 2007.

32 BFM, In die Schweiz eingereiste Ausländer nach Einwanderungsgrund, 5.2006-4.2007, <http://www. bfm.admin.ch $>>$ Themen $>$ Statistiken $>$ Ausländerstatistik $>$ Aktuelle Ergebnisse $>$ April 2007.

33 „Regroupement familial : la Suisse procède déjà à des tests ADN“, Le Temps, 20. September 2007.

34 Debatte über Familienzusammenführung und DNA-Tests lanciert, <http://www.humanrights.ch/home/de/ Schweiz/Politik/Asylpolitik/Umsetzung/idart_5364-content.html> (Konsultation: 14. Dezember 2007). Schweizerisches Parlament, 07.3761. Motion. Gesuche um Familiennachzug. DNA-Tests. Eingereicht von Carlo Sommaruga im Nationalrat, 5. Oktober 2007.

35 John Dupraz, Landwirtschaft und Arbeitsbedingungen in Europa, doc. 11114, Ausschuss für Umwelt, Landwirtschaft und kommunale und regionale Angelegenheiten, Parlamentarische Versammlung, Europarat, 20. Dezember 2006. 
heitlichte Regelungen und für verschärfte Sanktionen bei Verstössen gegen das Arbeitsrecht ${ }^{36}$.

In einem jüngeren Bericht empfahl der Europarat kollektive Regularisierungen als Instrument in der allgemeinen Politik und zur Verteidigung der Menschenrechte ${ }^{37}$. Angesichts der Tragweite der illegalen Einwanderung und des Bedarfs an einem europaweit abgestimmten Vorgehen plädiert der Europarat dafür, Regularisierungen zu erwägen und von Massnahmen wie verbesserter administrativer Behandlung und Bekämpfung von Schwarzarbeit zu begleiten. Ausserdem schlägt er die „Regularisierung nach Leistung“ vor, womit ein illegaler Migrant, der insbesondere die lokale Sprache gelernt hat, eine feste Arbeitsstelle besitzt und seine Steuern bezahlt, belohnt werden soll. Im Grunde handelt es sich um eine Regularisierung auf Fallbasis, wie sie eventuell von der Schweiz in Betracht gezogen werden könnte.

\subsubsection{Schengen und Dublin: Beteiligung der Schweiz am SIS-Übergangsmodell}

Das Schengener Informationssystem (SIS), die gemeinsame Fahndungsdatenbank der Mitgliedsstaaten des Schengener Raums, soll ausgebaut werden, um den Kampf gegen grenzüberschreitende Kriminalität und Terrorismus zu verstärken. Ausserdem soll das SIS beim Migrationsmanagement eingesetzt werden, das seit der Verabschiedung des Aktionsplans zur Bekämpfung der illegalen Einwanderung und des Menschenhandels am 28. Februar 2002 und des Aktionsplans für den Grenzschutz an den Aussengrenzen vom 13. Juni 2002 zunehmende Bedeutung gewinnt ${ }^{38}$.

In diesem Rahmen werden die Informationen für Europol und Eurojust zugänglich sein und können an Drittländer und -organe übermittelt werden. Der Schutz der Personendaten gewinnt dadurch an Bedeutung; er muss bestimmten europäischen Normen entsprechen. Gemäss dem Schengener Abkommen stehen allen Personen - ob Staatsangehörige eines Schengen-Raum-Mitglieds oder nicht Zugriffsrechte, Berichtigungsrechte und die einschlägigen Rechtsmittel zu.

Die Schweiz will die Abkommen von Schengen und Dublin möglichst rasch anwenden. Das verbesserte Schengener System SIS II wird jedoch erst im Dezember 2008 betriebsfähig sein. Die Schweiz setzt künftig direkt auf SIS II ${ }^{39}$. In der Zwischenzeit hält sie sich an die Übergangslösung, die ab Ende 2007 operativ ist ${ }^{40}$.

Zur umfassenden Anwendung des Besitzstandes von Schengen und Dublin muss die Schweiz den Schengener Grenzkodex übernehmen und eine etwaige Einreiseverweigerung für Ausländer in einem Flughafen begründen. Die SFH verlangt, dass die Beschwerde gegen eine Einreiseverweigerung eine aufschie-

36 „L'Europe ouvre les yeux sur les esclaves de l'agriculture“, Le Courrier, 1. Februar 2007.

37 John Greenway, Regularisation Programmes for Irregular Migrants, doc.11350, Ausschuss für Wanderbewegungen, Flüchtlings- und Bevölkerungsfragen, Parlamentarische Versammlung, Europarat, 6. Juli 2007.

38 „Evolution du système d'information de Schengen“, Le Temps, 5. März 2007.

39 „Les frontières mieux surveillées“, Le Temps, 16. Februar 2007.

40 „,SISone4all“ auch für die Schweiz“, Neue Zürcher Zeitung, 16. Mai 2007. 
bende Wirkung besitzt ${ }^{41}$. Zudem sind die Luftfahrtgesellschaften künftig verpflichtet, den Behörden zur Bekämpfung der illegalen Einwanderung bestimmte Personendaten über ihre Passagiere bekannt zu geben. Dies erfordert eine Veränderung des neuen Ausländergesetzes ${ }^{42}$.

Die Europäische Union hat die Schweiz aufgefordert, im Rahmen des Schengen-Besitzstandes an FRONTEX, der gemeinsamen europäischen Agentur für die Kontrolle an den Aussengrenzen, mitzuwirken. Die Agentur ist seit 2005 operativ; sie unterstützt die Bemühungen der südlichen Länder gegen die illegale Immigration auf dem Seeweg. FRONTEX fehlt allerdings die erforderliche Ausstattung. Die Schweiz ist bereit, Personal und Material bereitzustellen; dieses Angebot wird jedoch erst nach dem für den 1. November 2008 vorhergesehenen Inkrafttreten des Assoziierungsabkommens von Schengen/Dublin - nach der Ratifizierung durch alle EU-Staaten - konkretisiert werden.

\subsection{Integrationspolitik}

Nachdem die Aufnahme mit der Annahme des Ausländer- und des Asylgesetzes geregelt wurde, steht nun die Integrationsfrage in der Politik und in den Medien im Vordergrund. Seit dem letzten Jahr konzentriert sich die Diskussion besonders auf den Integrationsvertrag. Das neue Ausländergesetz und die neue Integrationsverordnung sehen dieses Instrument vor, überlassen es aber den Kantonen, ob sie davon Gebrauch machen wollen. Integrationsvereinbarungen umfassen in der Regel die Pflicht, Sprachkurse zu besuchen; sie sind für Migranten vorgesehen, die Probleme haben bzw. individuelle Förderung benötigen. Bestimmte Kreise verlangen jedoch, diese Verträge flächendeckend einzusetzen.

[D] Jahrbuch 2007, Nr. 1, „Integrationspolitik“, S. 202-204.

Die Eidgenössische Ausländerkommission (EKA) beschäftigte sich im September 2007 mit dieser Frage. Die EKA ist vor allem besorgt, dass die Integrationsvereinbarung diskriminierend wirken und besonders beim Familiennachzug eine gewisse Willkür herbeiführen könnte ${ }^{43}$. Sie bezweifelt auch die Wirksamkeit eines diesbezüglichen Obligatoriums; die Erfahrung zeigt nämlich, dass Integrationsvereinbarungen vor allem dann nützlich sind, wenn sie mit der Erschliessung konkreter Perspektiven, z.B. Zugang zum Arbeitsmarkt, zusammenhängen.

\subsubsection{Integration:} innerstaatliche Massnahmen und internationale Klassifizierung

Das neue Ausländergesetz (AuG) regelt in erster Linie die Voraussetzungen für den Zugang von Staatsangehörigen aus Drittländern in die Schweiz, der künftig hauptsächlich hoch qualifizierten Erwerbstätigen gewährt wird. Das AuG, das am 1. Januar 2008 in Kraft getreten ist, legt die Leitlinien zur Integration fest.

41 SFH, Stellungnahme zu den Gesetzesänderungen im Rahmen der Umsetzung der Assoziierung mit Schengen/Dublin, 28. Juni 2007, <http://www.osar.ch/2007/05/30/stn_schengen> (Konsultation: 14. Dezember 2007).

42 EJPD, Neues Verfahren bei Einreiseverweigerungen an der Grenze, Medienmitteilung, 28. März 2007.

43 EKA, Integrationsvereinbarungen: EKA ist skeptisch, Medienmitteilung, 11. September 2007. 
Integration wird darin als gegenseitiger Prozess definiert, welcher sowohl die Bereitschaft von Ausländerinnen und Ausländern zur Integration als auch die Offenheit der Aufnahmegesellschaft voraussetzt. Integration gilt als ein gemeinsames Ziel für alle Migrantinnen und Migranten und schliesst Flüchtlinge und vorläufig aufgenommene Personen mit ein. Die Förderung der Integration ist primär Aufgabe der Regelstrukturen; spezifische Massnahmen für Migrantinnen und Migranten sind nur ergänzend und subsidiär angezeigt ${ }^{44}$.

Die Verordnung über die Integration von Ausländerinnen und Ausländern (VIntA) legt die Schwerpunkte im Bereich der Integration fest. Die Förderung des Spracherwerbs und die Verbesserung der Allgemeinbildung bilden die Priorität des Schwerpunkteprogramms 2008-2011. Das EJPD unterstützt zudem über Leistungsverträge die Einrichtung von regionalen Integrationsarbeitszentren, die Ausländern Hilfe und professionelle Dienstleistungen von interkulturellen Übersetzern anbieten. Dieser zweite Schwerpunkt soll bis Ende 2011 im heutigen Umfang kofinanziert werden. Schliesslich können gemäss dem dritten Schwerpunkt innovative Pilotprojekte finanziert werden. Über die Hälfte der verfügbaren 16,5 Millionen Franken wird der Sprachausbildung gewidmet.

\section{$\square$ Spracherwerb}

Es herrscht ein allgemeiner Konsens darüber, dass die Migranten die lokale Sprache beherrschen müssen. Allerdings kommt nach bestimmten Äusserungen die Unkenntnis der lokalen Sprache eher selten vor: Christoph Blocher habe selbst eingeräumt, dass nur einer von 15 Ausländern keine der Landessprachen beherrsche $^{45}$. Andere Kreise wünschen eine einschneidendere Politik ab der ersten Stunde oder wenden ein, der Massnahmenkatalog sei nicht besonders innovativ ${ }^{46}$. Dessen ungeachtet ist es möglich, dass die Gewährung einer Niederlassungsbewilligung - nur für Staatsangehörige von Drittstaaten - künftig vom Erwerb der lokalen Sprache abhängt.

In den Monaten vor den Parlamentswahlen am 21. Oktober 2007 wurde die Wahlkampagne weitgehend von diesem Thema beherrscht. Die Kantone präsentierten stolz ,ihre“ Integrationsmodelle: Besonders Neuenburg besitzt langjährige Erfahrungen im Bereich der politischen Einschliessung von Ausländern (kommunales Stimm- und Wahlrecht) und der diskreten, effizienten Dialogarbeit mit Vertretern von Migranten. Gleiches gilt für Basel, das sich selbst mit der Einführung des Integrationsvertrags laut und deutlich als Avantgarde proklamiert. Die im Basler Kantonsgesetz verankerte Integrationsvereinbarung soll mit bestimmten Ausländern abgeschlossen werden, die eine Aufenthaltsbewilligung erwarten. Das zugleich anspruchsvolle und freiwillige Basler Modell gilt besonders in der Deutschschweiz als Massstab. Es führt zu lebhaften Auseinandersetzungen, besonders weil diese Initiative die Politik auf Bundesebene inspirieren könnte. Die Schweizerische Volkspartei (SVP) hält das Dispositiv für zu kostspielig, die Linke missbilligt das Junktim zwischen Aufenthaltsbewilligung und - zumal erfolgreichem - Besuch von Sprachkursen, während andere darin eine Diskriminierung sehen, weil die Vereinbarung nur für Staatsangehörige von Drittländern gilt. Schliesslich fragt sich auch, ob Integration überhaupt

44 BFM, Schwerpunkteprogramm für die Jahre 2008-2011, Bern, 17. Juli 2007.

45 „La langue reste la clé de voûte de l'intégration“, Le Temps, 23. August 2007.

46 „Intégration: le Conseil fédéral mise sur l'apprentissage des langues“, Le Temps, 23. Oktober 2007. 
aufgezwungen werden darf: Christoph Meier, Integrationsbeauftragter der Stadt Zürich, erklärte dazu, man könne die Integration nur fördern und erleichtern ${ }^{47}$.

\section{$\square$ Jugendgewalt}

Ende Juni 2007 schickte das Bundesamt für Justiz einen Bericht über die Jugendgewalt in die Vernehmlassung. Der Bericht geht von der Feststellung aus, dass die Gewaltdelikte von Jugendlichen seit 1999 und 2006 gestiegen sind, und nennt verschiedene Ursachen dafür, darunter ,die mangelnde elterliche Aufsicht, ein inkonsequenter Erziehungsstil, schulische Probleme, die Zugehörigkeit zu einer gewalttätigen Clique, soziale Benachteiligung, der kulturelle Hintergrund oder die ungenügende Integration ausländischer Jugendlicher“ ${ }^{\star 48}$.

Als Massnahmen schlägt der Bericht namentlich vor, dass die Kantone bei der Wegweisung straffälliger Ausländer eine konsequentere und nachhaltigere Praxis verfolgen sollen und dass die Überprüfung der Einbürgerungsvoraussetzungen durch verbindliche Richtlinien verbessert wird ${ }^{49}$. In seinem Kommentar zu diesem Bericht betonte der Kirchenbund, dass Delikte von ausländischen Jugendlichen mit jugendstrafrechtlichen, nicht mit ausländerrechtlichen Massnahmen geahndet werden müssten; das Jugendstrafrecht gelte für schweizerische wie auch für ausländische Jugendliche ${ }^{50}$.

\section{$\square$ Migrant Integration Policy Index}

Die Integration, innenpolitisches Thema par excellence, wird nur selten aus einem strikt vergleichenden Blickwinkel untersucht. Dieser Herausforderung stellt sich der Migrant Integration Policy Index (MIPEX) mit einer Untersuchung, die von der Europäischen Gemeinschaft finanziert und vom British Council und der Migration Policy Group (welche die Federführung und die Zusammenarbeit zahlreicher lokaler Forscher gewährleisteten) geleitet wurde. Bei MIPEX handelt es sich um die breiteste je durchgeführte systematische Studie zu 140 Feldern der Integrationspolitik in den 25 Mitgliedsstaaten der Europäischen Union sowie in Norwegen, in der Schweiz und in Kanada; Kanada wird wegen seiner Integrationspolitik häufig zum Vorbild genommen. Dabei wurden sechs politische Handlungsbereiche betrachtet: Zugang zum Arbeitsmarkt, Familienzusammenführung, feste Aufenthaltsbewilligung, politische Beteiligung, Erwerb der Staatsbürgerschaft, Schutz vor Rassismus und Diskriminierung.

Der Ländervergleich kam zum Schluss, dass das Integrationspotenzial der schweizerischen Politik gegenüber der Migrantenbevölkerung global unter dem durchschnittlichen Integrationspotenzial der europäischen Länder liegt ${ }^{51}$. Die schweizerische Integrationspolitik wird hinsichtlich des Arbeitsmarktzugangs als gut bezeichnet, hinsichtlich der Bekämpfung der Diskriminierung dagegen

47 „Un ,contrat d'intégration“ pour les nouveaux venus à Bâle-Ville“, Le Temps, 15. März 2007.

48 Bundesamt für Justiz, Jugendgewalt. Ausmass, Ursachen und Massnahmen, Bern, EJPD, 29. Juni 2007.

49 EJPD, Massnahmenpaket gegen die Jugendgewalt. EJPD schickt Bericht zur Stellungnahme an interessierte Kreise, Medienmitteilung, 29. Juni 2007.

50 Schweizerischer Evangelischer Kirchenbund, Prävention steht im Vordergrund, Medienmitteilung, 31. August 2007.

$51<\mathrm{http}: / / w w w . i n t e g r a t i o n i n d e x . e u>$ (Konsultation: 14. Dezember 2007). 
als mittelmässig. Der Vergleich zeigt ferner, dass in der Schweiz Gesetze zum Verbot der Diskriminierung bei der Arbeit und in der Gesellschaft völlig fehlen, während die EU-Länder in den letzten Jahren ein rechtliches Instrumentarium entwickelt und verabschiedet haben ${ }^{52}$.

\subsubsection{Einbürgerungen: Diskussion weiterhin aktuell}

Das Thema Einbürgerung, das in den letzten Jahren ganz oben auf der politischen Agenda stand, verzeichnete 2007 mehrere Entwicklungen.

Zum einen erreichte die Zahl der Einbürgerungsentscheide im Jahr 2006 mit 47607 neuen Schweizer Bürgerinnen und Bürgern einen Rekord; dies bedeutet eine Zunahme um 20\% gegenüber 2005. Personen aus Serbien stehen an erster Stelle der Einbürgerungen (11 701), gefolgt mit grossem Abstand von Personen aus Italien (4591) und aus der Türkei (3457). Diese Zunahme hat mehrere Gründe: Verringerung der Einbürgerungskosten, kontinuierlich wachsende Zahl von Personen, die die Kriterien der Aufenthaltsdauer erfüllen, um sich für den Schweizer Pass bewerben zu können, sowie die Angst vor einer künftigen Verschärfung der Einbürgerungspolitik.

Zum anderen steht die Regelung der Einbürgerung im Fadenkreuz einer erbitterten politischen Schlacht. Im Jahr 2003 hatte das Bundesgericht ein richtungsweisendes Urteil gefällt, wonach die Einbürgerungsentscheide die Grundrechte der Kandidaten erfüllen müssen: Sie müssen angehört werden, dürfen nicht diskriminiert werden und haben Anspruch auf einen begründeten Entscheid. Diese Forderung verunmöglicht de facto einen Entscheid an der Urne.

Als Reaktion auf die als ,ppolitisch“ beurteilte Rechtsprechung ${ }^{53}$ reichte die SVP die Volksinitiative „Für demokratische Einbürgerungen“ ein. Diese Initiative fordert erstens, dass die Gemeinden weiterhin selbstständig festlegen sollen, welches Organ das Gemeindebürgerrecht erteilt, und zweitens, dass Einbürgerungsentscheide endgültig sein sollen (d.h. ohne Überprüfungsmöglichkeit durch eine andere Behörde). Der Bundesrat beantragte den eidgenössischen Räten die Ablehnung der Volksinitiative, weil nach seiner Meinung der angestrebte Ausschluss jeglicher gerichtlicher Überprüfung kommunaler Einbürgerungsentscheide mit dem Völkerrecht nicht vereinbar sei ${ }^{54}$. Dagegen empfahl er die parlamentarische Initiative des freisinnigen Aargauer Ständerats Thomas Pfisterer als indirekten Gegenentwurf:55 Danach soll der Volksentscheid gestattet werden, sofern die Ablehnungen begründet werden und den abgewiesenen Kandidaten der Rechtsweg offen- steht.

[D] Jahrbuch 2007, Nr. 1, „Einbürgerungen“, S. 203-204.

Im März 2007 sprach sich die Staatspolitische Kommission des Nationalrates nach dem Prinzip „Nein gegen die Herrschaft der Richter“ mit 13 zu 12 Stimmen überraschend für die SVP-Volksinitiative aus ${ }^{56}$. Im Oktober 2007 kam der

52 „La Suisse, mouton noir de la lutte contre la discrimination“, Le Courrier, 16. Oktober 2007.

53 „Naturalisation: le Tribunal fédéral aux prises avec sa jurisprudence“, Le Temps, 11. Mai 2006.

54 Bundesrat, Botschaft zur Eidgenössischen Volksinitiative „Für demokratische Einbürgerungen“, 25. Oktober 2006 (BB1 2006 8953).

55 EJPD, Bundesrat lehnt Volksinitiative ,für demokratische Einbürgerungen“ ab, Medienmitteilung, 25. Oktober 2006.

56 „Neuregelung der Einbürgerung droht zu scheitern“, Neue Zürcher Zeitung, 19. Februar 2007. 
Nationalrat jedoch auf diesen Standpunkt zurück und erklärte, dass nur die Gemeindeversammlungen befugt seien, Einbürgerungsentscheide zu fällen.

Daneben werden viele weitere Aspekte der Einbürgerung diskutiert: Information über die Einbürgerungskandidaten, Frist für eine etwaige Aberkennung der Staatsbürgerschaft und Nichtigerklärung für straffällige Jugendliche ausländischer Herkunft. Die Staatspolitische Kommission des Nationalrates hat den Umfang der Informationen über die Kandidaten bestimmt, die die Kantone den Gemeindeversammlungen liefern müssen: Sie lehnte es ab, dass Aussagen zu Invalidität, Sozialhilfe und Steuerzahlungen gemacht werden, stimmte aber zu, dass die Konfession zu den Grundinformationen zählen soll - zum grossen Bedauern der Eidgenössischen Kommission gegen Rassismus, die darin eine Diskriminierungsgefahr sieht.

Gegenwärtig verfügt das BFM über eine Frist von fünf Jahren, um die schweizerische Staatsbürgerschaft denjenigen, die sie auf betrügerische Weise erworben haben (generell durch eine Scheinehe), wieder zu entziehen. Im Jahr 2005 wurde das Schweizer Bürgerrecht in 29 Fällen aberkannt, 2006 in 52 Fällen. Eine parlamentarische Initiative schlägt vor, die Frist für die Aberkennung von fünf auf acht Jahre zu erstrecken ${ }^{57}$. Im Vernehmlassungsverfahren wurde der Vorschlag von 21 Kantonen befürwortet und von fünf Kantonen abgelehnt ${ }^{58}$.

Die Diskussion zur Einbürgerung geht jedoch noch weiter: Es ist die Rede vom Entzug des Passes wegen Vorkommnissen, die bis zu zehn Jahre nach dem Erwerb des Schweizer Bürgerrechts auftreten und die die Staatssicherheit nicht beeinträchtigen. Einige Parlamentarier haben den Bundesrat aufgefordert, die erforderlichen Gesetze so anzupassen, dass bei der Erhebung von Statistiken über Kriminalität und Sozialversicherungen auf Bundesebene frisch Eingebürgerte (bis fünf Jahre) in einer separaten Kategorie erfasst werden ${ }^{59}$. Diese Motion ist noch nicht behandelt worden.

Diese Schritte müssen unter anderem mit der Diskussion um delinquente Jugendliche ausländischer Herkunft in Verbindung gebracht werden. Mehrere stark mediatisierte Ereignisse wurden von den politischen Parteien in der Kampagne vor den Parlamentswahlen, bei der dann das Thema Migranten und Integration im Vordergrund stand, aufgegriffen.

5705.463 Parlamentarische Initiative. Scheinehen unterbinden / 06.414 Parlamentarische Initiative. Änderung Bürgerrechtsgesetz. Nichtigkeitserklärung. Fristerstreckung, Website der Christlichdemokratischen Volkspartei, <http://www.cvp.ch/de/documents/doc_docdetail- $-0 \_0-0-0-4777 . h$ tml> (Konsultation: 15. November 2007).=gelb markiert i.O. so ?

58 BFM, Zusammenfassung der Vernehmlassungsergebnisse 06.414n Parlamentarische Initiative Lustenberger Änderung Bürgerrechtsgesetz. Nichtigerklärung. Fristausdehnung, November 2007, $<$ http://www.parlament.ch/D/Dokumente/ed-spk-06-014-vernehmlassungsergebnisse-d.pdf> (Konsultation: 14. Dezember 2007).

59 Schweizerisches Parlament, 06.3848. Motion. Berücksichtigung von Eingebürgerten bei der Erhebung von Statistiken, eingereicht von Thomas Müller im Nationalrat, 20. Dezember 2006. „Ausländerpolitik mit der Statistik“, Neue Zürcher Zeitung, 9. Februar 2007. „,Ich bin überrascht über Blochers Vorgehen.' Die St. Galler Polizeidirektorin wehrt sich gegen die Vereinnahmung des Themas Jugendgewalt durch den Bund“, NZZ am Sonntag, 11. Februar 2007. 


\subsubsection{Ausländer im Mittelpunkt der Wahlkampagne}

Die Annahme des neuen Asyl- und des neuen Ausländergesetzes mit einer überwiegenden Mehrheit der Stimmbürger im September 2006 verlieh den Bewegungen, die die Ausländerthematik politisieren, Auftrieb, ihren Kurs mit Blick auf die Parlamentswahlen im Herbst 2007 fortzusetzen. So wurden mehrere Themen in die politische Arena eingebracht. Im Mai 2007 lancierten gewisse Parlamentarier - Agrarvertreter, die sich in der „Egerkinger Gruppe“ zusammengeschlossen hatten - die eidgenössische Volksinitiative gegen den Bau von Minaretten in der Schweiz ${ }^{60}$, die als „Ausdruck religiös-politischer Machtansprüche, welche den Religionsfrieden durchaus gefährden können“"61, betrachtet werden. Im Juli 2007 verzichteten die SVP-Delegierten jedoch auf eine offizielle Stellungnahme zur Initiative. Bestimmte Beobachter betonten, diese Initiative gehöre abgesehen vom Argument der Wahlkonjunktur zu einer langen Tradition der religiösen Intoleranz, die früher den Juden gegolten habe und heute den Muslimen gelte ${ }^{62}$.

Im Juli 2007 lancierte die SVP synchron mit dem Vernehmlassungsverfahren über die Jugendgewalt (siehe oben Abschnitt 12.5.1) eine weitere Initiative, die die systematische Ausschaffung von Ausländern fordert, die schwere Delikte begangen haben oder die Sozialhilfe missbrauchen ${ }^{63}$. Die Initianten verlangen, dass die heutigen Kann-Bestimmungen des neuen Ausländergesetzes zwingend gestaltet werden, um die als laxistisch beurteilte einschlägige Praxis der Richter zu flankieren ${ }^{64}$. Im Fall von minderjährigen Delinquenten wird vorgeschlagen, die ganze Familie auszuschaffen, um ein kriminelles Familienmitglied zu bestrafen ${ }^{65}$. Wie die britische Zeitung The Independant ${ }^{66}$ festhält, wurden solche Bestrafungen seit der Sippenhaft des Naziregimes in Europa nicht mehr praktiziert.

Wie bereits zuvor sorgte diese Initiative für neuen Zündstoff in der Debatte über die Grenzen der direkten Demokratie. Die Frage lautet, ob Vorschläge, die völkerrechtlichen Grundverträgen wie z.B. der Europäischen Menschenrechtskonvention zuwiderlaufen, gar nicht zur Abstimmung gebracht werden sollen oder ob das Volk unter allen Umständen das letzte Wort hat. In den letzten 30 Jahren hat sich die Doktrin mit der Entwicklung des Völkerrechts, das das ehemals vorherrschende Konzept des Vorrangs der Volksrechte modifizierte, verändert. Der Genfer Verfassungsrechtler Andreas Auer meint dazu, zeitgenössische Staaten, auch direkte Demokratien, seien im Bereich der Menschenrechte nicht mehr souverän ${ }^{67}$.

$60<$ http://www.admin.ch/ch/d/pore/vi/vis353.html> (Konsultation: 14. Dezember 2007).

61 Ulrich Schlüer, Minarett-Gegner koordinieren Anstrengungen, <http://www.svp.ch/index.html?page_ $\mathrm{id}=2565 \& 1=2>$ (Konsultation : 14. Dezember 2007).

62 „La peur du minaret cache une aversion plus profonde“, Domaine public, Nr. 1731, 5. Mai 2007.

63 „Ausschaffungs-Initiative zustandegekommen. 200000 Unterschriften für die Abschiebung krimineller Ausländer“, Neue Zürcher Zeitung, 16. Oktober 2007.

64 „Le populisme pénal à l'œuvre. L'initiative de l'UDC pour le renvoi des étrangers criminels s'inscrit dans un courant général inquiétant", Domaine public, Nr. 1740, 23. Juli 2007.

65 „Weniger jugendliche Kriminelle“, NZZ am Sonntag, 11. Februar 2007.

66 „Switzerland: Europe's Heart of Darkness?““, The Independent, 7. September 2007.

67 Andreas Auer und Bénédicte Tornay, „Aux limites de la souveraineté du constituant: l'initiative ,Pour des naturalisations démocratiques“", Pratique juridique actuelle, Nr. 6, 2007, S. 740 ff. Gegenwärtig ist in Deutschland eine ähnliche Auseinandersetzung um die Grenzen des Nationalstaats gegenüber dem Völkerrecht im Gange: „Zweifel an Mehmet-Klausel. Richterin kritisiert Regel zur Ausweisung von Straftätern“, Süddeutsche Zeitung, 13. November 2007. 
In der Wahlkampagne wurden auch aggressive Töne angeschlagen: Die Polemik betraf insbesondere eine Plakatkampagne und einen Videoclip der SVP ${ }^{6}$, die als rassistische Äusserungen kritisiert wurden. Die ausländische Presse zeigte sich alarmiert über die fremdenfeindliche Stimmung in der Schweiz ${ }^{69}$, was die besorgte Analyse von Doudou Diène, Sonderberichterstatter der Vereinten Nationen über zeitgenössische Formen des Rassismus, zu erhärten scheint.

[D] Jahrbuch 2008, Nr. 1, Kapitel 9, Abschnitt 9.1.6, Unterabschnitt „Interventionen des Sonderberichterstatters über Rassismus in der Schweiz“.

Doudou Diène bedauerte in seinem Bericht über die Schweiz, der im März 2007 dem Menschenrechtsrat unterbreitet wurde, dass Gesetze und Politiken zu Immigrations- und Asylfragen nur aus der Perspektive der Sicherheit behandelt wür$\operatorname{den}^{70}$. Der Autor forderte die Schweiz auf, eine kohärente nationale Gesetzgebung zur Repression des Rassismus zu erlassen, wie dies in den von der Schweizerischen Eidgenossenschaft unterzeichneten völkerrechtlichen Urkunden verlangt werde, besonders im internationalen Übereinkommen zur Beseitigung jeder Form von Rassendiskriminierung und im Aktionsprogramm von Durban.

Das Carrefour de réflexion et d'action contre le racisme anti-Noir en Suisse (CRAN) erklärte, es schliesse sich dem Bericht von Doudou Diène an ${ }^{71}$, während die Behörden nuanciert auf den ersten internationalen Bericht über die Situation in der Schweiz reagierten: Sie räumten ein, dass Rassismus, ein unannehmbarer Verstoss gegen die Menschenrechte, auch in der Schweiz vorkomme, aber von Einzelfällen könne nicht auf eine generelle Dynamik geschlossen werden; ausserdem verwiesen sie auf die bisher geleisteten Anstrengungen, dem Rassismus entgegenzutreten ${ }^{72}$.

\subsubsection{Fusion der EKA und der EKF}

Die Eidgenössische Ausländerkommission (EKA) und die Eidgenössische Kommission für Flüchtlingsfragen (EKF) wurden per 1. Januar 2008 zusammengelegt und bilden neu die Eidgenössische Kommission für Migrationsfragen (EKM). Diese Massnahme entspricht dem erklärten Ziel des Bundesrates nach vereinfachten Strukturen im Bereich der ausserparlamentarischen Kommissionen und ist eine logische Folge der Fusion des Bundesamtes für Zuwanderung, Integration und Auswanderung (IMES) und des Bundesamtes für Flüchtlinge (BFF) zum Bundesamt für Migration (BFM) am 1. Januar 2005.73

Die Verordnung über die Integration von Ausländerinnen und Ausländern (VIntA) beschreibt den Auftrag der neuen Kommission. Die bisher von der EKA und von der EKF geprüften Integrationsprojekte sollen künftig direkt dem

68 „Le paradis et l'enfer selon l'UDC: le clip qui choque, sur la forme et le fond“, Le Temps, 28. August 2007.

69 „Das schwarze Schaf Europas‘. Wie die internationalen Medien den schweizerischen Wahlkampf kommentieren“, Neue Zürcher Zeitung, 8. Oktober 2007.

70 „Doudou Diène: ,Il y a une dynamique xénophobe en Suisse““, Le Courrier, 27. März 2007.

71 Le CRAN en phase avec le rapport de Doudou Diène, Medienmitteilung, 27. März 2007, <http:// www.cran.ch>.

72 Eidgenössisches Departement des Innern, Bericht des UNO-Sonderberichterstatters über Rassismus über seinen Besuch in der Schweiz. Antwort des Bundesrates, Medienmitteilung, 27. März 2007.

73 EJPD, Ausländerkommission und Kommission für Flüchtlingsfragen werden zusammengelegt, Medienmitteilung, 31. Januar 2007. 
BFM unterstellt werden, das im Einklang mit dem Integrationsförderungsprogramm des Bundes über die Finanzhilfen entscheidet. Die neue Kommission ist ermächtigt, Stellungnahmen abzugeben und Vorschläge zu formulieren. Sie soll aus 30 Mitgliedern bestehen, ,wobei eine angemessene Vertretung von Ausländerinnen und Ausländern gewährleistet werden soll'"74.

\subsubsection{Verweigerung des Ausländerstimmrechts in Bern und Zürich}

In der Westschweiz haben alle Kantone bis auf das Wallis der ausländischen Wohnbevölkerung auf unterschiedliche Weise politische Rechte gewährt. In der Deutschschweiz wird das Prinzip nach wie vor weitgehend abgelehnt.

[Dahrbuch 2007, Nr. 1, „Stimmrecht für Ausländerinnen und Ausländer“, S. 204.

So wies der Zürcher Kantonsrat eine von der Regierung und von der Linken unterstützte Einzelinitiative zurück, die politische Rechte für Ausländer auf Gemeindeebene forderte ${ }^{75}$. Bereits zum fünften Mal wurde ein solcher Vorschlag auf Kantonsebene abgeschmettert. Auch in Bern sprach sich der Grossrat im Januar 2007 zum zweiten Mal in zwei Jahren mit 77 zu 73 Stimmen gegen dieses Recht aus. Die von der Berner Regierung unterstützte Vorlage wurde vom bürgerlichen Lager vehement bekämpft ${ }^{76}$.

\section{QUELLEN}

Augenauf, Bulletin, Bern, Ausgaben 2007.

Bundesamt für Migration, Asylstatistik 2006, Januar 2007.

Bundesamt für Migration, Medienmitteilungen, Ausgaben 2007.

Centres de contact Suisses-Immigrés, Carrefour, Ausgaben 2007.

Schweizerische Flüchtlingshilfe, Asyl, Schweizerische Zeitschrift für Asylrecht und Praxis, Bern, Ausgaben 2006-2007.

Schweizerische Flüchtlingshilfe, Chronologie der Flüchtlingspolitik, Ausgaben 2007.

Schweizerische Flüchtlingshilfe, Fluchtpunkt, Ausgaben 2007.

Vivre ensemble, Liaison-Bulletin zur Verteidigung des Asylrechts, Genf, Ausgaben 2007.

\section{INTERNET-ADRESSEN}

Bundesamt für Migration: <http://www.bfm.admin.ch>.

Bundesverwaltung: <http://www.admin.ch>.

Carrefour de réflexion et d'action contre le racisme anti-Noir en Suisse (CRAN) : <http://www.cran.ch>.

European Council on Refugees and Exiles (ECRE), Europäischer Flüchtlingsrat, Koordination von Nichtregierungsorganisationen für Ayslbewerber und Flüchtlinge : <http://www.ecre.ch>

Hochkommissariat der Vereinten Nationen für Flüchtlinge : <http://www.unhcr.ch>.

Human Rights Watch: <http://www.hrw.org >.

Institut für Politikwissenschaft der Universität Bern : <http://www.anneepolitique.ch>.

Le Courrier : <http://www.lecourrier.org>.

Menschenrechte Schweiz MERS - Praktische Hilfsinstrumente für die Bildungsarbeit zu Menschenrechtsthemen: <http://www.humanrights.org>.

Schweizerische Beobachtungsstelle für Asyl- und Ausländerrecht: <http://www.migrantsrightswatch.ch>, $<\mathrm{http}: / /$ www.stopexclusion.ch/beobachtungsstelle $>$.

Schweizerische Flüchtlingshilfe: <http://www.osar.ch>.

74 Ibid.

75 „Nein zu Ausländerstimmrecht in den Gemeinden. Einzelinitiative im Kantonsrat chancenlos. Regierungsrat, SP und Grüne unterliegen deutlich“, Neue Zürcher Zeitung, 11. Februar 2007.

76 Swissinfo, In Bern weiterhin kein Simmrecht für Ausländer, 23. Januar 2007. 
Schweizerisches Parlament: <http://www.parlament.ch/d/Pages/welcomepage.aspx>.

Solidarité sans frontières (Zusammenarbeit der BODS und der Asylkoordination) : <http://www.sosf.ch $>$.

Swisspolitics.Org: <http://www.swisspolitics.org >. 